Research Article

\title{
Is Physical Activity Associated with Mental Health among Chinese Adolescents during Isolation in COVID-19 Pandemic?
}

\author{
Sifan Kang, Yuliang Sun, Xinxin Zhang, Fangjun Sun, Bingqi Wang, Wenfei Zhu* \\ School of Physical Education, Shaanxi Normal University, Xian 710119, China
}

\section{ARTICLE INFO}

\section{Article History}

Received 09 July 2020

Accepted 04 September 2020

Keywords

Physical activity

mood states

adolescents

COVID-19

\begin{abstract}
Background: Restricted outdoor activities and online learning during COVID-19 pandemic may pose threats on the physical and mental health of Chinese adolescents in middle schools. The study was to explore the relationship of Physical Activity (PA) and Sedentary Time (SED) with mood states among Chinese adolescents during the pandemic.

Methods: A total of 4898 adolescents (16.3 \pm 1.3 years old) from 49 middle schools in 13 urban and rural areas in Yan'an, China volunteered to participate in this study and completed online questionnaires. International Physical Activity Questionnaire (IPAQ) were used to measure PA and SED, and Profile of Mood States were used to evaluate mood states. We used MannWhitney $U$-test and Kruskal-Wallis test to assess differences in PA and SED in different sex and grade group, respectively. Mixed linear regression was used to analyze the relationship between PA/SED and mood states.
\end{abstract}

Results: Participants in our study accumulated $23.4 \pm 52.5$ min of moderate-to-vigorous PA and $363.6 \pm 148.4$ min of SED per day. The mood states of boys were better than that of girls $(p<0.01)$. The mood states of the students in Senior High School Grade 3 were at the highest level of mood disturbance. Higher levels of PA were significantly associated with lower levels of total mood disturbance in this population (High PA group according to IPAQ: $B=-3.22, \mathrm{SE}=0.40, p<0.001$; Moderate: $B=-1.47, \mathrm{SE}=$ $0.37, p<0.001$, compared to Low PA group).

Conclusion: Chinese adolescents maintained a sedentary lifestyle during the COVID-19 pandemic. Girls and students in Grade 3 Senior High School had higher level of mood disturbance. More PA was associate with improving mood state among adolescents in the pandemic. The present study may assist policymakers and healthcare professionals understand PA and mood states of Chinese adolescents during the epidemic and take targeted actions in case of emergencies in future.

(C) 2020 The Authors. Published by Atlantis Press International B.V. This is an open access article distributed under the CC BY-NC 4.0 license (http://creativecommons.org/licenses/by-nc/4.0/).

\section{INTRODUCTION}

The novel Coronavirus Disease (COVID-19), as a public health emergency of international concern, outbroke in Wuhan, China in 2019. To date, the disease has spread worldwide and infected 7,796,517 patients globally (84,730 in China) by 14 June 2020 [1]. The World Health Organization (WHO) declared COVID-19 a pandemic, and the epidemic disease was a global physical and mental health threat [2].

During emergencies, emotional problems are one of the most prominent social concerns, [3], and people are more likely to have negative emotions such as worry, panic, and confusion [4]. Mental health problems are difficult to address in pandemic and may have devastating consequence if remains untreated [5]. Long periods of social isolation, anxiety, and mental disorders increase the risk of mental illness [6,7]. In the COVID-19 outbreak, studies reported that there has been a high prevalence of mental health problems

Corresponding author.Email: wzhu@snnu.edu.cn

Data availability statement: The data that support the findings of this study are available from the corresponding author, [WZ], upon reasonable request.
$[8,9]$, and caused major psychological problems in common people [10], including emotional stress, anxiety, depression and other symptoms [11,12]. However, research focusing on the physical and mental health impact of large-scale emergencies like COVID-19 was still limited.

Since the outbreak of the COVID-19, nationwide school closures have been one of the most important policy interventions adopted by the Chinese government. Due to a long time of home isolation, and repeated delays in the start of school, there existed a great threat on the daily life routines, as well as physical and mental health of adolescents in middle schools. Additionally, the schedule of the Chinese National College Entrance Examination (Gao Kao) has been the focus of people's attention. Students in Grade 3 Senior High school were under big study pressure during the isolation caused by COVID-19. Adolescents were in a high-risk period of depression [13], and excessive life events and pressure may induce difficult-to-adjust emotions and psychological health problems [14]. With reductions in daily movement and huge academic learning pressure in an isolated environment, it is very necessary to investigate the PA levels and emotional state of adolescents during the epidemic to promote their healthy growth and study efficiency. 
At present, the world prevalence of physical inactivity in children and youth was at a concerning level [15]. A large number of studies suggest that young people accumulate at least $60 \mathrm{~min}$ of Moderateto-Vigorous intensity Physical Activity (MVPA) per day, while limiting Sedentary Time (SED) to $<120 \mathrm{~min}$ per day $[16,17]$. However, in a survey covering 105 countries, $80.3 \%$ of $13-15$-year-olds doing fewer than $60 \mathrm{~min}$ of MVPA per day [18]. In the context of the COVID-19 pandemic, daily transportation PA and leisure-time exercise were very limited. Most people spent longer time on sedentary behaviors at home, resulting in reduced Physical Activity (PA) [19]. In particular, long-term online academic learning was the major study method for adolescents during the COVID-19 pandemic. It inevitably led to lower levels of PA, and prolonged sedentary screen time. Insufficient PA level of adolescents was associated with increased anxiety level, decreased learning efficiency and increased risk of depression [20]. Research has approved that increase in SED resulted in poor mental health [21,22]. High levels of regular PA can reduce students' anxiety and stress and improve their on academic performance [23]. Physical exercise have a favorable effect on various mood profiles, regardless of exercise types, duration (between 10 and $60 \mathrm{~min}$ ) and recovery period (between 5 and $30 \mathrm{~min}$ ) [24,25]. Young people with severe mental illness showed reductions in anxiety and depression after the exercise intervention [26]. During the epidemic, adolescents maintaining moderate-intensity PA was associated with better immune function and better health conditions [27].

Countries and areas all around the world have launched home PA guides for adolescents, and many foreign websites have also launched youth physical exercise methods. Experts and scholars in public health and exercise science have put forward suggestions for at-home PA during the epidemic [28,29], and provide scientific guidance for maintaining healthy. In April 2020, the General Administration of Sport in China issued a guidance document on the physical health of young people during the epidemic. Exercise was recommended to improve wellbeing and learning efficiency and keep a good emotional state during COVID-19 epidemic. However, no study has reported the association between PA and mental health in Chinese adolescents during the COVID-19 pandemic.

This study was to investigate whether PA and SED of adolescents were related to their mood states and mental health during the isolation period caused by COVID-19 pandemic. We hypothesized that PA was negatively associated with mood disturbances among Chinese adolescents during the COVID pandemic, and higher PA was related with low levels of mood disturbances. The finding will help develop methods and strategies to support people to overcome the outbreak of pandemics or social isolation and provides advices for policymakers and health care professionals to enhance the practice of PA in future public health emergencies.

\section{MATERIALS AND METHODS}

\subsection{Sample and Study Design}

This study was a cross-sectional study conducted in the period between March 8th and 15th, 2020 after the Director-General of WHO declared the COVID-19 outbreak a public health emergency. A total of 4898 students $(16.3 \pm 1.3$ years old $)$ participated in the survey, which was from 49 middle schools in Yan'an City. Yan'an City is a prefecture-level city located in the north of Shaanxi Province. It is a holy place for Chinese revolution and the first batch of national historical and cultural cities announced by the State Council. This survey included a total of 11 counties (Huangling, Huanglong, Yichuan, Luochuan, Fuxian, Yanxian, Ganquan, Yanchuan, Wuqi, Zichang, and Zhidan) and two districts (Pagoda and Ansai), including urban and rural areas. In China, middle schools include Junior High Schools and Senior High Schools. Specifically, Junior High Schools include Junior High School Grade 1-3, while Senior High Schools include Senior High School Grade 1-3. In our study, participants were divided into four groups: Junior Grade 1 and 2, Junior Grade 3, Senior Grade 1 and 2, Senior Grade 3, depending on whether they were in the graduating grade or not. The questionnaires were filled out by students with the guidance of their teachers through the google forms platform Questionnaires included three domains: demographic information (age, sex, grades, living areas, wake up time, bed time, etc.), PA/SED and mood states. A total of 5500 questionnaires were issued and 5319 questionnaires were received (response rate: $96.7 \%$ ), with 4898 having complete and valid data of demographic information, PA/SED and mood states. Participants has signed written consents to participate. The study was approved by the ethics committee of Shaanxi Normal University.

\subsection{Measures}

The International Physical Activity Questionnaire Short Form (IPAQ-SF) - Chinese version were used to measure the PA levels among adolescents in the present study. The IPAQ-SF was translated by Macfarlane et al. [30] and can be considered adequately reliable instrument to assess the total amount of MVPA obtained in common people. The IPAQ-SF consists of vigorous-intensity activities, moderate-intensity activities, and walking. Participants were required to recall the number of days they performed each activity (frequency) and the length of time (duration) they were involved daily in each activity during the last 7 days [31]. According to the official IPAQ-SF scoring protocol, the PA level was divided into three PA groups, including high, moderate and low PA group (see www.ipaq.ki.se). The average time spent on sedentary behaviors in each of the last 7 days was also asked in the survey. Participants were divided by the order of SED from low to high into three groups (high, moderate, and low SED group) according to the SED tertiles.

The mood states of those adolescents were measured through the simplified Chinese Profile of Mood States (POMS) revised by Zhu [32]. The POMS scale is a self-rating questionnaire consisting of seven mood dimensions, which was a reliable and valid method of assessing a variety of mood states $(r=0.65,-0.93$; Cronbach $\%=$ 0.87-0.95) [33,34]. Participants were indicated to "describe how they have been feeling during the past week, including today" on 5 -point scales (anchors: $0=$ not at all, $1=$ a bit less, $2=$ intermediate, 3 = more, 4 = extremely) [22]. The test described the current state experienced by the individuals. The equation of the Total Mood Disturbance (TMD) score was: TMD = negative mood scales score (tension, depression, anger, fatigue, and confusion) positive mood scales score (vigor and self-esteem) +100 . Higher TMD scores indicated a greater degree of mood disturbance, depressed, or disordered (Low: TMD $\leq 207$, Moderate: 207-287, High: $\geq 288$ ) [35]. 


\subsection{Statistical Analysis}

All statistical analyses were performed using the version 21.0 SPSS (Chicago, IL, USA). Descriptive statistical analyses were conducted to calculate the means and standard deviations for PA, SED and POMS variables. As the PA and SED variables were not normally distributed, non-parametric tests (Mann-Whitney $U$-test and Kruskal-Wallis test) were conducted to assess differences in PA and SED among different sex and grade groups. Similarly, nonparametric tests (MannWhitney $U$-test and Kruskal-Wallis test) were used to analyze the scores of different sex and grade groups. As the PA and SED were significantly skewed $(p<0.01)$, PA/SED categories (high, moderate, and low) were used in mixed liner regression models to analyze the association of PA/SED with mood states, with PA or SED groups as the independent variables, mood states as the dependent variable, and sex, grades and residential area as the covariates. Statistical significance was set at $p<0.05$.

\section{RESULTS}

Participants ( $16.3 \pm 1.3$ years old) in this study included 2359 boys (48\%) and 2539 girls (52\%), with 2943 Junior High School students and 1955 Senior High School students (Table 1). Descriptive characteristics of the population sample are shown in Table 1. During the epidemic period most students (75\%) got up at 6:00-8:00 a.m. and went to sleep before 23:00 (88\%) at night.

In Table 2, the total MVPA of adolescents was $23.4 \pm 52.5 \mathrm{~min} /$ day. For boys, the total MVPA was $27.8 \pm 65.0 \mathrm{~min} /$ day, and vigorous $\mathrm{PA}$ accounted for the largest proportion. In the girl group, the total MVPA was $19.2 \pm 36.8 \mathrm{~min} /$ day, with vigorous PA accounting for the largest proportion. Boys accumulated significantly more vigorous PA than girls, while girls had more moderate PA $(p<0.01)$. The SED of boys and girls were $340.2 \pm 149.4$ and $346.8 \pm 147.4 \mathrm{~min} /$ day, respectively. The SED levels of girls were significantly higher than

Table 1 Descriptive characteristics of participants $(N=4898)$

\begin{tabular}{lrc}
\hline Variables & $\boldsymbol{n}$ & $\%$ \\
\hline Sex & 2359 & 48 \\
$\quad$ Boys & 2539 & 52 \\
$\quad$ Girls & & \\
Grade & 1652 & 34 \\
$\quad$ Junior High School Grade 1 and 2 & 1291 & 26 \\
$\quad$ Junior High School Grade 3 & 1117 & 23 \\
$\quad$ Senior High School Grade 1 and 2 & 838 & 17 \\
Senior High School Grade 3 & & \\
Residential area & 2652 & 54.1 \\
Rural & 2246 & 45.8 \\
$\quad$ Urban & & \\
Wake-up time & 103 & 2 \\
Before 6:00 & 3667 & 75 \\
6:00-8:00 & 1009 & 21 \\
8:00-10:00 & 119 & 2 \\
After 10:00 & & \\
Bed time & 471 & 10 \\
20:00-21:00 & 1774 & 36 \\
21:00-22:00 & 2075 & 42 \\
22:00-23:00 & 578 & 12 \\
After 23:00 & & \\
\hline
\end{tabular}

Table 2 Comparison of physical activity and mood state of adolescents of different genders $(N=4898)$

\begin{tabular}{lccc}
\hline & $\begin{array}{c}\text { Total } \\
(\boldsymbol{n}=\mathbf{4 8 9 8})\end{array}$ & $\begin{array}{c}\text { Boys } \\
(\boldsymbol{n}=\mathbf{2 3 5 9})\end{array}$ & $\begin{array}{c}\text { Girls } \\
(\boldsymbol{n}=\mathbf{2 5 3 9})\end{array}$ \\
\hline $\begin{array}{l}\text { Physical activity } \\
\text { Moderate and vigorous } \\
\text { (min/day) }\end{array}$ & $23.4 \pm 52.5$ & $27.8 \pm 65.0$ & $19.2 \pm 36.8^{* *}$ \\
$\quad$ Vigorous (min/day) & $10.6 \pm 24.2$ & $13.6 \pm 28.8$ & $7.9 \pm 18.5^{* *}$ \\
Moderate (min/day) & $14.4 \pm 27.5$ & $13.6 \pm 26.8$ & $15.1 \pm 28.2^{* *}$ \\
Walking (min/day) & $12.8 \pm 42.6$ & $14.2 \pm 53.5$ & $11.4 \pm 28.8$ \\
$\quad$ Sedentary time (min/day) & $363.6 \pm 148.4$ & $340.2 \pm 149.4$ & $346.8 \pm 147.4^{* *}$ \\
Profile of mood states & & & \\
Tension & $3.4 \pm 2.7$ & $3.3 \pm 2.8$ & $3.5 \pm 2.7^{* *}$ \\
$\quad$ Anger & $3.0 \pm 2.6$ & $2.9 \pm 2.7$ & $3.0 \pm 2.6^{* *}$ \\
Fatigue & $4.5 \pm 3.9$ & $4.4 \pm 4.0$ & $4.6 \pm 4.0^{*}$ \\
$\quad$ Depression & $2.5 \pm 2.4$ & $2.5 \pm 2.4$ & $2.6 \pm 2.5$ \\
Confusion & $2.5 \pm 1.8$ & $2.4 \pm 1.9$ & $2.5 \pm 1.8^{* *}$ \\
$\quad$ Vigor & $5.6 \pm 2.4$ & $5.5 \pm 2.6$ & $5.5 \pm 2.4^{* *}$ \\
$\quad$ Self-esteem & $4.4 \pm 1.9$ & $5.0 \pm 2.1$ & $4.9 \pm 1.9$ \\
$\quad$ Total mood disturbance & $102.7 \pm 10.6$ & $102.4 \pm 10.9$ & $103.3 \pm 10.3^{* *}$ \\
\hline
\end{tabular}

The statistical significance between sex groups is marked with "*”. "Indicates $p<0.05$, "indicates $p<0.01$.

boys $(p<0.01)$. The scores of tension, anger, and confusion were significantly higher in girls than those in boys $(p<0.01)$. The score of vigor was higher in girls than that in boys. TMD of girls was also significantly higher than boys $(p<0.01)$. There was no significant difference in PA and mood state between rural and urban adolescents $(p>0.05$, not included in the tables).

Table 3 has shown that the total PA, moderate PA, and walking PA were significantly different in different grade groups $(p<0.01)$. The total PA of the Junior Grade 1 and 2 was the lowest, and the Senior Grade 3 was the highest. Significant difference existed in the SED among grades $(p<0.01)$, with Junior Grade 3 was the shortest, while the Senior Grade 3 group was the longest. For mood states, significant differences existed across different grade groups in the scores of tension, anger, fatigue, depression, confusion and total mood disturbance $(p<0.01)$, with the scores were lowest in Junior Grade 1 and 2, and highest in Senior Grade 3.

Table 4 showed higher PA level were significantly related to lower negative mood scores and higher positive mood scores $(p<0.01)$. By comparing the mood states of different SED groups, there was no significant association between SED and the mood state in this population $(p>0.05)$.

Figure 1 showed significant differences existed in the total negative mood scores across different sex, grade and PA groups, respectively. Boys, adolescents in lower grades, and those with higher PA indicated significantly lower levels of total negative mood scores $(p<0.01)$. Also, significant difference existed in the total positive mood scores across different PA groups $(p<0.01)$. No significant differences have been found in the total positive scores in different sex or grade groups, respectively $(p>0.05)$.

\section{DISCUSSION}

This study was one of the first to examine the association between PA and mood state of adolescents of different sexes and grades in the context of the COVID-19 outbreak. The study found boys, 
Table 3 Comparison of physical activity and state of mind among adolescents of different grades $(N=4898)($ Mean \pm SD)

\begin{tabular}{lcccc}
\hline & $\begin{array}{c}\text { Junior Grade } \mathbf{1} \\
(\boldsymbol{n}=\mathbf{1 6 5 2})\end{array}$ & $\begin{array}{c}\text { Junior Grade } \mathbf{3} \\
(\boldsymbol{n}=\mathbf{1 2 9 1})\end{array}$ & $\begin{array}{c}\text { Senior Grade 1 and 2 } \\
(\boldsymbol{n}=\mathbf{1 1 1 7})\end{array}$ & $\begin{array}{c}\text { Senior Grade 3 } \\
(\boldsymbol{n}=\mathbf{8 3 8})\end{array}$ \\
\hline Physical activity & & & & \\
$\quad$ Moderate and vigorous (min/day) & $20.3 \pm 43.4$ & $22.8 \pm 70.6$ & $25.6 \pm 45.0$ & $27.3 \pm 44.6^{* *}$ \\
$\quad$ Vigorous (min/day) & $9.7 \pm 22.5$ & $10.8 \pm 25.7$ & $11.1 \pm 25.0$ & $11.5 \pm 23.9$ \\
Moderate (min/day) & $12.2 \pm 26.8$ & $13.4 \pm 25.2$ & $16.6 \pm 28.8$ & $17.3 \pm 30.1^{* *}$ \\
Walking (min/day) & $10.6 \pm 32.1$ & $12.0 \pm 63.0$ & $14.6 \pm 32.5$ & $15.8 \pm 32.1^{* *}$ \\
Sedentary time (min/day) & $340.0 \pm 143.2$ & $331.8 \pm 141.4$ & $339.4 \pm 149.0$ & $374.7 \pm 163.8^{* *}$ \\
Profile of mood states & & & & \\
Tension & $3.2 \pm 2.7$ & $3.5 \pm 2.7$ & $3.2 \pm 2.6$ & $4.1 \pm 2.8^{* *}$ \\
Anger & $2.7 \pm 2.6$ & $2.9 \pm 2.6$ & $3.0 \pm 2.6$ & $3.6 \pm 2.7^{* *}$ \\
Fatigue & $4.1 \pm 3.5$ & $4.4 \pm 3.9$ & $4.6 \pm 4.0$ & $5.5 \pm 4.3^{* *}$ \\
Depression & $2.3 \pm 2.1$ & $2.4 \pm 2.4$ & $2.5 \pm 2.5$ & $3.0 \pm 2.7^{* *}$ \\
Confusion & $2.2 \pm 1.8$ & $2.3 \pm 1.8$ & $2.7 \pm 1.80$ & $3.0 \pm 1.9^{* *}$ \\
Vigor & $5.6 \pm 2.6$ & $5.7 \pm 2.5$ & $5.5 \pm 2.4$ & $5.5 \pm 2.2$ \\
Self-esteem & $4.9 \pm 2.0$ & $5.0 \pm 1.9$ & $5.0 \pm 1.7$ & $4.9 \pm 1.7$ \\
Total mood disturbance & $101.6 \pm 9.9$ & $102.4 \pm 10.7$ & $103.1 \pm 10.6$ & $105.8 \pm 11.2^{* *}$ \\
\hline
\end{tabular}

The statistical significance among grade groups is marked with " “*”. *Indicates $p<0.05$, "*indicates $p<0.01$.

Table 4 Relationship ${ }^{a}$ between physical activity level, sedentary time and state of mood of adolescents

\begin{tabular}{|c|c|c|c|c|c|c|c|}
\hline & \multirow{2}{*}{ Low } & \multicolumn{3}{|c|}{ Moderate } & \multicolumn{3}{|c|}{ High } \\
\hline & & $B$ & SE & $p$-value & $B$ & SE & $p$-value \\
\hline \multicolumn{8}{|l|}{ Physical activity levels ${ }^{b}$} \\
\hline Tension & Ref. & -0.07 & 0.09 & 0.45 & -0.15 & 0.10 & 0.16 \\
\hline Anger & Ref. & -0.27 & 0.09 & $<0.001^{* *}$ & -0.42 & 0.10 & $<0.001^{*}$ \\
\hline Fatigue & Ref. & -0.34 & 0.14 & $0.01^{*}$ & -0.72 & 0.15 & $<0.001^{* *}$ \\
\hline Depression & Ref. & -0.21 & 0.08 & $0.01^{*}$ & -0.42 & 0.09 & $<0.001^{*}$ \\
\hline Confusion & Ref. & -0.15 & 0.06 & $0.02^{*}$ & -0.41 & 0.07 & $<0.001^{*}$ \\
\hline Vigor & Ref. & 0.59 & 0.08 & $<0.001^{* *}$ & 0.95 & 0.09 & $<0.001^{*}$ \\
\hline Self-esteem & Ref. & 0.31 & 0.06 & $<0.001^{* *}$ & 0.57 & 0.07 & $<0.001^{*}$ \\
\hline Total mood disturbance & Ref. & -1.47 & 0.37 & $<0.001^{* *}$ & -3.22 & 0.40 & $<0.001^{*}$ \\
\hline \multicolumn{8}{|l|}{ Sedentary time levels ${ }^{c}$} \\
\hline Tension & Ref. & 1.40 & 2.80 & 0.62 & 1.50 & 2.98 & 0.61 \\
\hline Anger & Ref. & 3.60 & 2.82 & 0.20 & 1.50 & 3.00 & 0.61 \\
\hline Fatigue & Ref. & 5.40 & 4.01 & 0.18 & 1.50 & 4.27 & 0.72 \\
\hline Depression & Ref. & 2.60 & 2.52 & 0.30 & 1.00 & 2.68 & 0.71 \\
\hline Confusion & Ref. & 2.90 & 2.04 & 0.15 & 1.75 & 2.17 & 0.80 \\
\hline Vigor & Ref. & 4.40 & 2.70 & 0.10 & 3.25 & 2.87 & 0.26 \\
\hline Self-esteem & Ref. & 3.10 & 2.12 & 0.79 & 4.00 & 2.12 & 0.14 \\
\hline Total mood disturbance & Ref. & 5.80 & 11.11 & 0.60 & 1.00 & 11.84 & 0.93 \\
\hline
\end{tabular}

adjusted for sex, grade, residential location. ${ }^{\mathrm{b}}$ According the official International Physical Activity Questionnaire Short Form scoring protocol, Low group, $n=2863$; Moderate, $n=1150$; High, $n=885$. 'Sedentary time level, it was based on the tertiles of sedentary time, Low group, $n=1633$; Moderate, $n=1633$; High, $n=1632$; The statistical significance is marked with " "*”. "Indicates $p<0.05$, "*indicates $p<0.01$.

adolescents in lower grades, and those with higher PA indicated significantly lower levels of negative mood states. PA was related to the mood state of adolescents, and higher levels of PA was associated with better mood states. Our study provided a realistic basis for support young people to cope with emergencies and social isolation and promote their physical and mental health during the COVID-19 pandemic.

Adolescents in our study spent an average of $23.4 \pm 52.5 \mathrm{~min} /$ day on MVPA and $363.6 \pm 148.4 \mathrm{~min} /$ day on sedentary behaviors per day, and they were less active than those in previous research [36,37]. For example, the Mielgo-Ayuso et al. [38] survey found that the weekly total PA of adolescents (13-17 years) was $936.8 \pm$ $762.5 \mathrm{~min} /$ week, a total of $55.4 \%$ of children and adolescents performed $<60 \mathrm{~min} /$ day of MVPA [36]. Rääsk et al. [37] studied the PA of adolescent boys using an accelerometer (average age 14 years) and found their MVPA was $56.4 \pm 25.0$ (min/day). Additionally, recent studies have found PA levels of common people have declined during the COVID-19 epidemic [39-41]. Long-term home isolation during the outbreak and online learning or working may be the reason for less PA and more SED.

During the epidemic period, the total mood disturbance of adolescents was at a relatively low level, and their mood state was stable in this study. Since the survey was conducted in a steady growth phase of the epidemic in March 2020, most students have already adapted to the isolation environment and their feelings of uneasiness decreased. By comparing the differences in the mood state of 

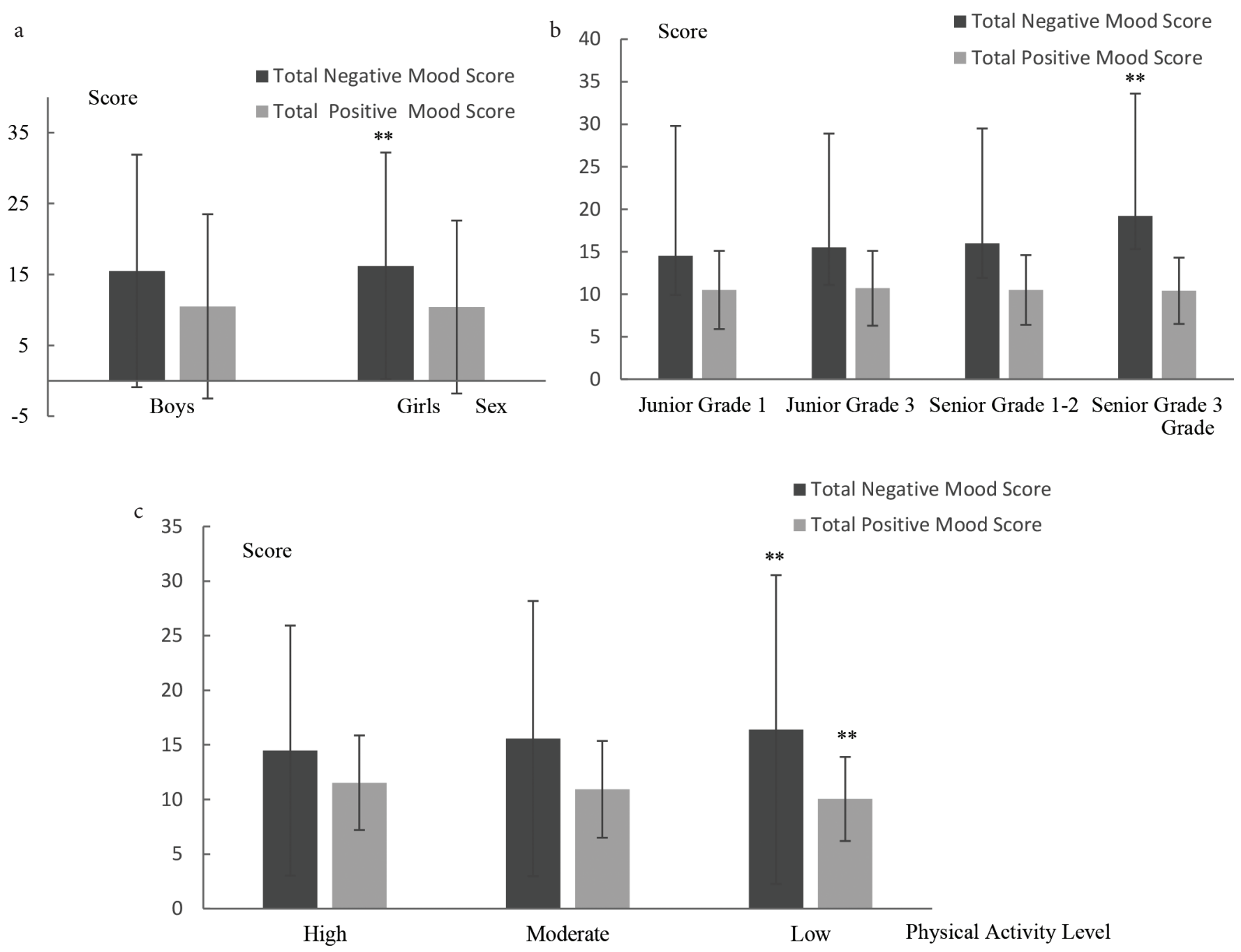

Figure 1 Total positive and negative mood scores in different groups (a. Scores in different sex groups, b. Scores in different grade groups, c. Scores in different physical activity groups). The statistical significance in different groups is marked with “*”, respectively. * Indicates $p<0.05$, “*indicates $p<0.01$.

students of different sexes, we found the mood state of boys and girls were significantly different, and the value of girls' total mood disturbance was higher than boys. The reason may be that the psychological and physical characteristics of girls in middle-school were more sensitive to various things than boys, and girls were more likely to produce tension and confusion in the face of emergencies. This was consistent with previous studies [42]. The total mood disturbance of the Senior Grade 3 was the highest, and significant differences existed in the mood states across different grade groups. The reason may be that the school study of the Junior Grade 3 group and Senior High Grade 3 group have been delayed for nearly 3 months, and their study efficiency and environment were very limited. More specifically, the pressure of the high school entrance examination and National College Entrance Examinations has caused students to be emotionally unstable and psychologically anxious. The students in the Junior Grade 1 and 2 have just entered the middle-school and the learning pressure was relatively small, so their state of mood was a stable level. A survey of general public (12-59 years) at the initial phase of COVID-19 outbreak in China indicated about one-third people had moderate-to-severe anxiety, and students and women were more prone to have higher stress and anxiety [43]. Affected by the epidemic, the start of school was postponed, and online learning became the main learning method for students. A survey found that online learning for more than $2.5 \mathrm{~h}$ per week can cause severe mood disturbance. Research has approved that the longer time students spent in front of the screen, the lower levels of psychological well-being $[44,45]$. Therefore, in future pandemic, relevant departments should control online learning time and pay attention to the physical and mental health of adolescents.

Significant association has been found between PA and mood states in this population. Higher levels PA was related to better performance in mood states tests, which was consistent with previous studies $[46,47]$. For example, survey of Chinese college students' emotions and physical exercise after the outbreak found that physical exercise helped to alleviate negative emotions, and when weekly PA was 2500 Metabolic Equivalent of Energy (METs), it could more significantly alleviate negative emotions [41]. Li [48] found that moderate-intensity PA can help reduce the negative emotions of college students and produce positive mood states. Xu et al. [49] investigated the PA and mood state of the 18-69-year-old population and found PA was significantly related to the mood state of the residents, and physical exercise helped to reduce panic and depression. 
Another study among 2678 (18-65 years) individuals with mood and/or anxiety disorders found that a large proportion of patients with mood and/or anxiety disorders did not exercise regularly, and those who exercise regularly had a low level of anxiety and higher levels of satisfaction with life [50]. In a review article covering 73 articles on the effects of PA on the mental health of children aged 3-18, it was reported that exercise had a small to moderate positive effect on the mental health of children, especially for children who were diagnosed as cognitively impaired or emotionally disturbed [47]. Compared to lower level PA, individuals engaging in higher PA had lower odds of experiencing anxiety, while there was no significant difference for moderate levels of PA [51]. In the context of the COVID-19 epidemic, research has found a significant positive correlation existed between PA and mental well-being, and maintaining higher levels of MVPA was an important strategy for mental health [52]. People who accumulated exercise for more than $30 \mathrm{~min}$ during the epidemic were less likely to experience symptoms such as anxiety and depression, while those who were sedentary for more than $10 \mathrm{~h}$ a day had higher levels of depression $[53,54]$.

In this study, we found that SED was not significantly associated with mood state. The reason may be that sedentary behaviors were not specifically classified in our study. Research has shown that the depression level of adolescents with an average of more than $2 \mathrm{~h}$ a day in front of the screen was significantly higher than that of adolescents who have not [55-57]. Adolescents with longer time of screen behaviors were at higher levels of anxious [57]. However, some other studies have also found SED was not associated with depression [58,59], since mental health are influenced by many other factors, such as education, income and history of other disease. Longitudinal investigation is needed to further discuss the relationship between SED and mood state. Intervention activities such as the online exercise teaching and training should be used to further explore the impact of exercise on mood states of different population during emergencies.

The strengths of our study included: first, the sample size of the study was large, and including adolescents of different sexes, grades and areas (rural and urban). During the COVID-19 epidemic, the National College Entrance Examination has been the focus of public attention, and the population in our study was very representative and the results can provide some suggestions for students resume their daily PA and help to protect them from the negative mood during the COVID-19 crisis. Second, the IPAQ-SF and POMS were internationally recognized and have high reliability and validity, which can effectively provide the data needed for this survey, Third, the study was conducted during the outbreak of COVID-19, which was a public pandemic with global health threats. The results in such a unique social model was valuable for policymakers, schools, communities and families to design and implement strategies to ensure the PA and mental health in Chinese adolescents. The present study had several limitations. First, both PA and mood states were measured by self-reported tools, which may suffer from the same source of bias in this study. However, this may be the only method to evaluate the PA and mood states of adolescents during the COVID-19 isolation. Second, due to lack of supervision and patience, the data collected by online questionnaires may not be very accurate and reliable. Third, the online survey was conducted from March 8th to 15 th, which was in a period of slow growth. Students have adapted to home isolation and online learning, and their mood state was relatively stable. In the future, further study can be conducted to investigate the objectively measured PA and sedentary behaviors of adolescents during emergencies and explore the exact relationship between PA/sedentary behaviors and emotional state.

\section{CONCLUSION}

The PA level was relatively low in Chinese adolescents during the COVID-19 pandemic. The TMD of the Senior Grade 3 students was relatively higher than those in other grades. PA were significantly associated with mood states, with higher levels of PA during home isolation were related to more stable mood states. Maintaining an active lifestyle can help to reduce students' anger, fatigue, depression and produce positive emotional states during the COVID-19 pandemic. PA and exercise are important components of intervention programs for future study aiming to help children and adolescents protect their mental health from adverse impact of public health emergencies like the COVID-19 pandemic.

\section{CONFLICTS OF INTEREST}

The authors declare they have no conflicts of interest. The funders had no role in the design of the study; in the collection, analyses, or interpretation of data; in the writing of the manuscript, or in the decision to publish the results.

\section{AUTHORS' CONTRIBUTION}

SF and WZ participated in the design of the study, contributed to data collection and analyses. YS and XZ contributed to data collection and analyses. FS and BW participated the data collection. All the authors participated in the manuscript writing. All the authors have read and approved the final version of the manuscript and agree with the order of the authorship.

\section{FUNDING}

This study was supported by the MOE (Ministry of Education in China) Project of Humanities and Social Sciences (20YJC890053, 16XJC890001), and Fundamental Research Funds for the Central Universities (GK201803094, GK201803095). The funding source(s) had no involvement in the work beyond providing a financial contribution.

\section{ACKNOWLEDGMENT}

The authors thank the other investigators, the staff, and the participants of the study for their valuable contributions.

\section{REFERENCES}

[1] World Health Organization. WHO Director-General's statement on IHR Emergency Committee on Novel Coronavirus (2019-nCoV). [Internet]. Geneva, Switzerland: World Health Organization; 2020 [cited February 9, 2020]. 
[2] Wang C, Horby PW, Hayden FG, Gao GF. A novel coronavirus outbreak of global health concern. Lancet 2020;395;470-3.

[3] Wang YN, Luo YJ. Specialty of mood disorders and treatment during emergent events of public health. Adv Psychol Sci 2003;11;387-92 (in Chinese).

[4] Fan P, Cheng Z, Zhang Y, Gao X, Mo X, Zhang X, et al. Analysis of the psychology and behavior of the people during the new epidemic pneumonia and countermeasures. Soc Sci Rev 2020;35;1-5.

[5] Ransing R, Adiukwu F, Pereira-Sanchez V, Ramalho R, Orsolini L, Teixeira ALS, et al. Mental health interventions during the COVID-19 pandemic: a conceptual framework by early career psychiatrists. Asian J Psychiatr 2020;51;102085.

[6] Zhang C. A survey \& study on college students' mental health state and the education countermeasures during the Novel Coronavirus Pneumonia. Psychologies 2020;15;44-6.

[7] Sani G, Janiri D, Di Nicola M, Janiri L, Ferretti S, Chieffo D. Mental health during and after the COVID-19 emergency in Italy. Psychiatry Clin Neurosci 2020;74;372.

[8] Guo J, Feng XL, Wang XH, van IJzendoorn MH. Coping with COVID-19: exposure to COVID-19 and negative impact on livelihood predict elevated mental health problems in Chinese adults. Int J Environ Res Public Health 2020;17;3857.

[9] Gao J, Zheng P, Jia Y, Chen H, Mao Y, Chen S, et al. Mental health problems and social media exposure during COVID-19 outbreak. PLoS One 2020;15;e0231924.

[10] Vindegaard N, Benros ME. COVID-19 pandemic and mental health consequences: systematic review of the current evidence. Brain Behav Immun 2020;S0889-1591(20)30954-5.

[11] Montemurro N. The emotional impact of COVID-19: from medical staff to common people. Brain Behav Immun $2020 ; 87 ; 23-4$.

[12] Torales J, O'Higgins M, Castaldelli-Maia JM, Ventriglio A. The outbreak of COVID-19 coronavirus and its impact on global mental health. Int J Soc Psychiatry 2020;66;317-20.

[13] Li JL, Chen X, Zhao CH, Xu Y. Prevalence of depression in Chinese children and adolescents: a meta-analysis. Chin J Child Health Care 2016;24;295-8 (in Chinese).

[14] Stikkelbroek Y, Bodden DH, Kleinjan M, Reijnders M, van Baar AL. Adolescent depression and negative life events, the mediating role of cognitive emotion regulation. PLoS One 2016;11;e0161062.

[15] Shen H, Yan J, Hong JT, Clark C, Yang XN, Liu Y, et al. Prevalence of physical activity and sedentary behavior among chinese children and adolescents: variations, gaps, and recommendations. Int J Environ Res Public Health 2020;17;3066.

[16] Hallal PC, Andersen LB, Bull FC, Guthold R, Haskell W, Ekelund $\mathrm{U}$, et al. Global physical activity levels: surveillance progress, pitfalls, and prospects. Lancet 2012;380;247-57.

[17] American Academy of Pediatrics. Committee on Public Education: American Academy of Pediatrics: children, adolescents, and television. Pediatrics 2001;107;423-6.

[18] Tremblay MS, Chaput JP, Adamo KB, Aubert S, Barnes JD, Choquette L, et al. Canadian 24-hour movement guidelines for the early years (0-4 years): an integration of physical activity, sedentary behaviour, and sleep. BMC Public Health 2017;17;874.

[19] Gallè F, Sabella EA, Da Molin G, De Giglio O, Caggiano G, Di Onofrio V, et al. Understanding knowledge and behaviors related to CoViD-19 epidemic in Italian undergraduate students. Int J Env Res Public Health 2020;17;3481.

[20] Hamer M, Patalay P, Bell S, David Batty G. Change in device-measured physical activity assessed in childhood and adolescence in relation to depressive symptoms: a general population-based cohort study. J Epidemiol Community Health 2020;74;330-5.

[21] Hoare E, Milton K, Foster C, Allender S. The associations between sedentary behaviour and mental health among adolescents: a systematic review. Int J Behav Nutr Phys Act 2016;13;108.

[22] DeMello MM, Pinto BM, Dunsiger SI, Shook RP, Burgess S, Hand GA, et al. Reciprocal relationship between sedentary behavior and mood in young adults over one-year duration. Ment Health Phys Act 2018;14;157-62.

[23] Norris R, Carroll D, Cochrane R. The effects of aerobic and anaerobic training on fitness, blood pressure, and psychological stress and well-being. J Psychosom Res 1990;34;367-75.

[24] McDonald D, Hodgdon J. The psychological effects of aerobic fitness training: research and theory. Recent Res Psychol $1991 ; 37 ; 443$.

[25] Crush EA, Frith E, Loprinzi PD. Experimental effects of acute exercise duration and exercise recovery on mood state. J Affect Disord 2018;229;282-7.

[26] Corbett S, Farris MS, MacQueen G, Addington J. Pilot aerobic exercise intervention for youth at-risk for serious mental illness. Early Interv Psychiatry 2020.

[27] Chen P, Mao L, Nassis GP, Harmer P, Ainsworth BE, Li F. Returning Chinese school-aged children and adolescents to physical activity in the wake of COVID-19: actions and precautions. J Sport Health Sci 2020;9;322-4.

[28] Chen P, Mao L, Nassis GP, Harmer P, Ainsworth BE, Li F. Coronavirus disease (COVID-19): the need to maintain regular physical activity while taking precautions. J Sport Health Sci 2020;9;103-4.

[29] Jiménez-Pavón D, Carbonell-Baeza A, Lavie CJ. Physical exercise as therapy to fight against the mental and physical consequences of COVID-19 quarantine: special focus in older people. Prog Cardiovasc Dis 2020;63;386-8.

[30] Macfarlane DJ, Lee CCY, Ho EYK, Chan KL, Chan DTS. Reliability and validity of the Chinese version of IPAQ (short, last 7 days). J Sci Med Sport 2007;10;45-51.

[31] Craig CL, Marshall AL, Sjöström M, Bauman AE, Booth ML, Ainsworth BE, et al. International physical activity questionnaire: 12-country reliability and validity. Med Sci Sports Exerc 2003;35;1381-95.

[32] Zhu L. Introduction to POMS Scale and simple Chinese Norm. J Tianjin Inst Sport 1995;10;35-7 (in Chinese).

[33] McNair DM, Lorr M, Droppleman LF. Manual for the Profile of Mood States (POMS). San Diego, CA: Educational and Industrial Testing Services; 1972, pp. 99-115.

[34] Nyenhuis DL, Yamamoto C, Lucheta T, Terrien A, Parmentier A. Adult and geriatric normative data and validation of the profile of mood states. J Clin Psychol 1999;55;79-86.

[35] Hajo S, Reed JL, Hans H, Tulloch HE, Reid RD, Prince SA. Physical activity, sedentary time and sleep and associations with mood states, shift work disorder and absenteeism among nurses: an analysis of the cross-sectional Champlain Nurses' Study. PeerJ 2020;8;e8464.

[36] Omorou AY, Langlois J, Lecomte E, Vuillemin A, Briançon S, PRALIMAP Trial Group. Adolescents' physical activity and sedentary behavior: a pathway in reducing overweight and obesity. The PRALIMAP 2-year cluster randomized controlled trial. J Phys Act Health 2015;12;628-35. 
[37] Rääsk T, Maëstu J, Lätt E, Jürimäe J, Jürimäe T, Vainik U, et al. Comparison of IPAQ-SF and two other physical activity questionnaires with accelerometer in adolescent boys. PLoS One 2017;12;e0169527.

[38] Mielgo-Ayuso J, Aparicio-Ugarriza R, Castillo A, Ruiz E, Ávila JM, Aranceta-Batrina J, et al. Physical activity patterns of the spanish population are mostly determined by sex and age: findings in the ANIBES study. PLoS One 2016;11;e0149969.

[39] Pietrobelli A, Pecoraro L, Ferruzzi A, Heo M, Faith M, Zoller T, et al. Effects of COVID-19 lockdown on lifestyle behaviors in children with obesity living in Verona, Italy: a longitudinal study. Obesity 2020.

[40] Hemphill NM, Kuan MT, Harris KC. Reduced physical activity during COVID-19 pandemic in children with congenital heart disease. Can J Cardiol 2020;36;1130-4.

[41] Zhang Y, Zhang H, Ma X, Di Q. Mental health problems during the COVID-19 pandemics and the mitigation effects of exercise: a longitudinal study of college students in China. Int J Environ Res Public Health 2020;17;3722.

[42] Liu Y, Zhang W, Cai J. Relation between anxiety and depression for lifestyle in junior high school students. Chinese Ment Health J 2017;31;235-40 (in Chinese).

[43] Wang C, Pan R, Wan X, Tan Y, Xu L, Ho CS, et al. Immediate psychological responses and associated factors during the initial stage of the 2019 coronavirus disease (COVID-19) epidemic among the general population in China. Int J Environ Res Public Health 2020;17;1729.

[44] Ussher MH, Owen CG, Cook DG, Whincup PH. The relationship between physical activity, sedentary behaviour and psychological wellbeing among adolescents. Soc Psychiatry Psychiatr Epidemiol 2007;42;851-6.

[45] Rodriguez-Ayllon M, Cadenas-Sánchez C, Estévez-López F, Muñoz NE, Mora-Gonzalez J, Migueles JH, et al. Role of physical activity and sedentary behavior in the mental health of preschoolers, children and adolescents: a systematic review and meta-analysis. Sports Med 2019;49;1383-410.

[46] De Moor MH, Beem AL, Stubbe JH, Boomsma DI, De Geus EJ. Regular exercise, anxiety, depression and personality: a population-based study. Prev Med 2006;42;273-9.

[47] Ahn S, Fedewa AL. A meta-analysis of the relationship between children's physical activity and mental health. J Pediatr Psychol 2011;36;385-97.
[48] Li H. The relationship between physical exercise and the emotional state of the underprivileged group of college students. J Capital Univ Phys Educ Sports 2015;27;80-4 (in Chinese).

[49] Xu B, Ji L, Xu B WX. Research on evaluating mental state of adult residents of our city by using POMS index. China Sport Sci 2003;23;28-32 (in Chinese).

[50] Pelletier L, Shanmugasegaram S, Patten SB, Demers A. Selfmanagement of mood and/or anxiety disorders through physical activity/exercise. Health Promot Chronic Dis Prev Can 2017;37;149-59.

[51] Stubbs B, Koyanagi A, Hallgren M, Firth J, Richards J, Schuch F, et al. Physical activity and anxiety: a perspective from the World Health Survey. J Affect Disord 2017;208;545-52.

[52] Maugeri G, Castrogiovanni P, Battaglia G, Pippi R, D’Agata V, Palma A, et al. The impact of physical activity on psychological health during Covid-19 pandemic in Italy. Heliyon 2020;6;e04315.

[53] Schuch FB, Bulzing RA, Meyer J, Vancampfort D, Firth J, Stubbs B, et al. Associations of moderate to vigorous physical activity and sedentary behavior with depressive and anxiety symptoms in self-isolating people during the COVID-19 pandemic: a cross-sectional survey in Brazil. Psychiatry Res 2020;292;113339.

[54] Stanton R, To QG, Khalesi S, Williams SL, Alley SJ, Thwaite TL, et al. Depression, anxiety and stress during COVID-19: associations with changes in physical activity, sleep, tobacco and alcohol use in Australian adults. Int J Environ Res Public Health 2020;17;4065.

[55] Asare M, Danquah SA. The relationship between physical activity, sedentary behaviour and mental health in Ghanaian adolescents. Child Adolesc Psychiatry Ment Health 2015;9;11.

[56] Cao H, Qian Q, Weng T, Yuan C, Sun Y, Wang H, et al. Screen time, physical activity and mental health among urban adolescents in China. Prev Med 2011;53;316-20.

[57] Maras D, Flament MF, Murray M, Buchholz A, Henderson KA, Obeid N, et al. Screen time is associated with depression and anxiety in Canadian youth. Prev Med 2015;73;133-8.

[58] Hume C, Timperio A, Veitch J, Salmon J, Crawford D, Ball K. Physical activity, sedentary behavior, and depressive symptoms among adolescents. J Phys Act Health 2011;8;152-6.

[59] Gross EF. Adolescent internet use: what we expect, what teens report. J Appl Dev Psychol 2004;25;633-49. 